\title{
BLAISE PASCAL'S NEW EXPERIMENTS ON VACUA.
}

Translated from the third volume of Pascal's works, Hachette. 1872, by Willard J. Fisher,

Worcester, Mass.

To THE READER.

My dear reader: Certain considerations hindering me from publishing at present a complete treatise, wherein I have reported a quantity of new experiments done by me on vacua, and the consequences which I have drawn from them, I have decided to give an account of the principal ones in this abstract, in which you will see in advance the plan of the whole work.

The occasion of these experiments is as follows: It is about four years since an experiment. was tried in Italy thus: A glass tube about four feet long with one end open, the other hermetically sealed, being filled with quicksilver, then the opening closed with the finger or otherwise, and being placed perpendicular to the horizon with the stopped opening downward, is plunged two or three finger-breadths into some more quicksilver contained in a vessel filled half with quicksilver, half with water; if the opening be unstopped, remaining the while submerged in the quicksilver of the vessel, the quicksilver in the tube will descend partly, leaving in the upper end of the tube a space empty in appearance, the lower end of the same tube remaining full of the same quicksilver up to a certain height. And if the tube be raised a little, so that the opening, previously dipped into the quicksilver of the vessel, leaves the quicksilver and comes into the region of the water, the quicksilver in the tubeascends with the water to the top of the tube and the two liquids are mingled in the tube; but finally all the quicksilver falls, and the tube is altogether full of water.

This experiment having been reported from Rome to Rev. Fr. Mersenne, Minimite at Paris, he announced it in France in the year 1644, not without exciting the admiration of all savants and amateurs. As by their reports it became famous everywhere, I learned of it from M. Petit, superintendent of fortifications, a man well versed in belles lettres, who had heard of it from Rev. Fr. Mersenne himself. At Rouen; therefore, we did it together, this M. Petit and I, the same as had been done in Italy, and we found detail for detail what had been reported from that country, without then observing anything new.

Then, reflecting by myself on the consequences of that experiment, I confirmed myself in the idea wherein I had always 
been, that a vacuum was not a thing impossible in nature, and that she did not avoid it with as much horror as many imagined. What forced me to this idea was the slight foundation which I saw for the maxim so (generally) received, that nature does not suffer a vacuum, which is based upon experiments for the most part entirely false, although held entirely reliable; and of the rest, some are far removed from contributing anything to the proof and show that nature abhors too great congestion, and not that it avoids a vacuum; and the most favorable prove nothing more than that nature has a horror of a vacuum, not that it cannot suffer one.

To the weakness of this as a principle, I would add the observations which we daily make about the rarefaction and condensation of the air which, as some have shown, can be condensed even to the thousandth part of the space formerly occupied by it, and expands so strongly; which I considered as necessarily so, either because there is much empty space between its parts, or because there is penetration of dimensions. But since the world as a whole did not accept this as proof, I believed that this Italian experiment was capable of convincing even those most biased as to the impossibility of a vacuum.

Nevertheless, the force of prejudice always finds objections which take away deserved credit. Some say that the top of the tube is full of the vapors of mercury; others talk of an imperceptible granulation of rarefied air; others, of a kind of matter which does not exist outside of their imagination; and all, conspiring to outlaw the vacuum, emulate one another in that faculty of the mind which they call subtlety in the schools, and which in the solution of real difficulties gives nothing but vain words without foundation. I therefore resolved to do experiments so convincing as to be proof against all possible objections; of such I made a great number at the beginning of this year, some of them related to the Italian experiment, others entirely unrelated and having nothing in common with it. They were so exact and so satisfactory that by their means I showed that a vessel as big as can be made can be rendered entirely empty of all the kinds of matter which fall under our senses, or which are known in nature; also, what force is necessary for producing a vacuum.

Moreover, I tested the height necessary for a siphon to produce the effect expected of it, above which limiting height it no longer acts, contrary to the opinion so universally held in the 
world through so many centuries; also, the small force needed to draw the piston of a syringe without any matter taking its place; and many other things which you will see in the complete work, wherein I design to show the force employed by nature to avoid a vacuum, and how she actually allows and suffers it in a large space, which is easily made empty of all forms of matter which fall under the senses. Hence, I have divided the complete treatise into two parts, the first containing at length an account of all my experiments and a recapitulation of what they mean, divided in several maxims; the second, the consequences which I have deduced from them, in several propositions, wherein I have showed that the space apparently vacuous, as it appeared in the experiments, is in fact empty of all the forms of matter which fall under the senses or are known in nature. In the conclusion I give my ideas on the subject of vacuum, and reply to possible objections. So, I content myself with demonstrating the existence of a large vacuum and $I$ leave it to savants and scientists to find out what happens in such a region; as, whether animals can live there; whether glass in it diminishes its refracting power; and everything one can do there; not mentioning this in the treatise, of which I have thought fit to give you this abstract in advance, since, having made these experiments at much expense and spent much trouble and time, I feared that somebody else who had not spent the time or the money or the pains, anticipating me, might give to the public facts of which he was not a witness, and so which he could not describe with the accuracy and the order necessary for proper deductions; no one having had tubes or siphons as long as mine, and few being willing to take the trouble to have them.

And since honorable people join to the general inclination of all men, to defend themselves in their just possessions, also that of refusing honor not due them, you will no doubt approve me likewise, defending myself against those who would wish to deprive me of any of the experiments which I here give you or promise you in the complete treatise, for they are my own invention; and against those who would attribute to me that Italian experiment just described, since it is not mine. Although I have done it in more ways than anyone else, with tubes twelve and even fifteen feet long, nevertheless I will not speak of that alone in this, not being its inventor, as I have no design of giving what is not my own, the fruit of my own ingenuity.

(On this, see letter printed at end. W. J.F.) 
Abstract of the First Part, Wherein Are Described the EXPERIMENTS.

Experiments.

I. A glass syringe with a well fitting piston is plunged entirely into water, and its opening is closed with the finger, so as to touch the piston at the bottom, for this purpose the hand and arm being put into the water; one has need of only a moderate force to withdraw the piston and separate it from the finger without the water entering in any way (something the philosophers have believed could not be done with any finite force); then the finger is felt to be strongly and painfully drawn in; the piston leaves a space empty in appearance, into which it does not seem that anything can have got, since it is completely surrounded with water that can have had no access, the opening being closed. If one draws the piston further out, the space empty in appearance becomes greater, but the finger feels no greater suction; and if one removes the syringe almost entirely from the water, so that only the opening remains immersed, with the finger closing it, then on removing the finger the water, contrary to its nature, rises with violence and entirely fills the space vacated by the piston.

II. A bellows thoroughly tight on all sides does the same thing with similar precautions taken, against the belief of the same philosophers.

III. A glass tube forty-six feet long, with one end open and the other hermetically sealed, filled with water, or, better, with red wine for better visibility, is then stopped and in that condition raised and placed perpendicular to the horizon with the stopped end down and immersed about a foot in a vessel full of water. If the opening is unstopped, the wine in the tube descends to a certain height, about thirty-two feet above the level of the water in the vessel, runs out and mixes with the water in the vessel, which it colors slightly, while it separates from the glass at the top, leaving a space about thirteen feet long, apparently empty, where it does not seem as if anything could have got in. If the tube be tipped, then the height of the wine in the tube decreases by the inclination, the wine ascends till it reaches the height of thirty-two feet; and if finally the tube be tipped just to the height of thirty-two feet, it is entirely filled, sucking in, moreover, the water which had been ejected by the wine; so that it is full of wine from the top to thirteen feet from the bottom, and full of water slightly tinted in the thirteen feet below. 
IV. A siphon with unequal legs, the longer fifty feet, the shorter forty-five, is filled with water and the two openings stopped and placed in two vessels of water, each immersed about a foot, so that the siphon is perpendicular to the horizon, and the water surface in one vessel is about five feet higher than that in the other. If the two openings be unstopped with the siphon in this condition, the longer leg does not draw the water from the shorter, and consequently not from the vessel in which it is, contrary to the beliefs of all philosophers and artizans; but the water falls in the two legs standing in the two vessels to just the same height as in the tube just described, reckoning the height from the surface of the water in each vessel; but after inclining the siphon below the height of about thirty-one feet, the longer leg draws the water from the vessel of the shorter one; and on raising it above this height, this stops, and both the two sides discharge each into its own vessel; and on lowering, the water in the longer draws the water in the shorter as before.

$V$. If into a fifteen foot tube sealed at one end and filled with water there be put a fifteen foot cord with a thread attached to its end (this is to be inserted into the water slowly, so that it may take it up little by little; air might somehow be inclosed in it) so that there is nothing outside the tube except the thread attached to the cord for drawing it out, and if the opening be immersed in quicksilver, when the cord is withdrawn little by little, the quicksilver rises proportionally until the height of the quicksilver added to the fourteenth part of the height of the remaining water is two feet three inches; then, as the cord is pulled the water leaves the top of the tube and leaves a space empty in appearance, which continually increases as one keeps on pulling the cord. If the tube be inclined, the quicksilver of the vessel enters, so that with sufficient inclination the tube is entirely filled with quicksilver and water which strikes the top of the tube violently, making the same sort of a noise or report as if the tube were broken; and in fact, it does run a risk of breaking. To get rid of the little bit of air which, so to speak, is lodged in the cord, one can do the same experiment with a number of little wooden cylinders attached together with a brass wire.

VI. A syringe with a perfectly fitted piston is put into quicksilver so that its opening is immersed at least an inch and the rest of the syringe stands perpendicularly outside. If the piston be drawn still further, the syringe remaining as described, the quicksilver enters through the opening of the syringe, rises 
and remains in contact with the piston until this has gone up in the syringe two feet three inches. Beyond this height, if the piston be drawn still further, it does not draw the quicksilver any higher, but this leaves the piston and remains constant at this height of two feet three inches; so that there is made a space empty in appearance, which becomes greater as the piston is drawn further. It is probable that the same thing happens in a suction pump, and that the water rises in this only to the height of thirty-one feet, which corresponds to two feet three inches of quicksilver. More remarkable is this, that the syringe, if weighed in this condition, without removing it from the quicksilver or moving it in any way, has the same weight, although the space apparently empty be as small as desired, as when, withdrawing the piston farther, we make this space as large as we choose, and that it always weighs the same as the body of the syringe together with the quicksilver contained at the height of two feet three inches with not any apparently empty space-that is, when the piston has not yet left the quicksilver in the syringe, but is at the point of breaking away from it, if it is pulled out ever so little. So that the apparently empty space, although all the bodies about it tend to fill it, causes no change in weight, and, whatever be the differences in size among such spaces, there is none among the weights.

VII. A siphon whose long arm is ten feet, short arm nine and a half, is filled with quicksilver and its two openings put into two vessels of quicksilver, each immersed about an inch, so that the quicksilver surface in one is about a half foot higher than that in the other. When the siphon is perpendicular, the long arm does not attract the quicksilver from the short; but the quicksilver, breaking at the top, descends in each arm and empties into the vessels and falls to the usual height of two feet three inches, measured from the surface of the quicksilver in each vessel. If the siphon be inclined, the quicksilver mounts again from the vessels into the tubes, fills them and commences to flow from the short arm into the long, and so empties its vessel. For this inclination of the tubes wherein is the apparent void, when they stand in any liquid; always draws the liquids from the vessels if the openings of the tubes are not closed, or draws the finger if it closes the openings.

VIII. The same siphon is completely filled with water and then with a cord, as above, the two openings being put into the same two vessels of quicksilver; when the cord is withdrawn 
by one of the openings, the quicksilver ascends from the vessels into both the two arms, so that the fourteenth part of the height of the water in one arm together with the height of the quicksilver which has ascended into it is equal to the fourteenth part of the height of the water in the other together with the height of the quicksilver which has ascended into it. The result is that this fourteenth part of the height of the water together with the height of the quicksilver in each arm is a height of two feet three inches; for them the water divides above and there is formed an apparently void space.

From these experiments and many others reported in the complete book, wherein are seen tubes of all lengths, sizes and shapes filled with different liquids, variously immersed in different liquids, carried from some into others, weighed in various fashions, and wherein are described the different attractions felt by the finger closing the tube with the apparent void, there are deduced readily these maxims:

\section{Maxims.}

I. That all bodies show a repugnance toward separation one from another, and to allowing an apparent void between them, i. e., that nature abhors this apparent void.

II. That this horror or repugnance of all bodies is no greater. toward allowing a large void than a little one; i. e., for separation by a large interval than by a small one.

III. That the force of this horror is limited, and equal to that with which water of a certain height, about thirty-one feet, tends to flow downwards.

IV. That the bodies which bound the apparent void have no tendency to fill it.

V. That this tendency is no stronger for filling a large void than for a little one.

VI. That the force of this tendency is limited, and always equal to that with which water of a certain height, about thirtyone feet, tends to flow downwards.

VII. That a force greater, but as little greater as one chooses, than that with which water of a height of thirty-one feet tends to flow down is enough to cause the sufferance of this apparent void, even as large as one may wish, i. e., to cause bodies to be disunited by an interval as great as one may choose, provided that there is no other obstacle to their separation or displacement except the horror which nature has for the apparent void.

('There then follow eight propositions denying the existence 
of a plenum of various imagined sorts and asserting that the "space void in appearance" of the preceding actually contains no known kind of matter, real or hypothetical, including vapors of liquids; then an abstract of the conclusion expressing his opinion, thus:)

Wherefore I shall call a real vacuum that which $I$ have shown as an apparent vacuum, and I will hold for true the maxims given above, and enounce them for the absolute vacuum as I have for the apparent, thus:

(Here follow the maxims above, but with the word apparent omitted from connection with void or vacuum. And, finally, the statement of and reply to certain objections.)

\section{Objections.}

I. That the proposition that there is empty space is repugnant to common sense.

II. That the proposition, nature abhors a vacuum and nevertheless allows it, accuses nature of impotence, which implies a contradiction.

III. That numerous experiences, even everyday, show that nature cannot suffer a vacuum.

IV. That an imperceptible matter, unheard of and unknown to all the senses, fills such a space.

V. That light being either an accident or a substance, it is not possible for it to exist in a vacuum, being an ${ }^{s}$ accident, and that it fills the space void in appearance, being a substance.

(A letter of Pascal to M. de Ribeyre, "Premier président de a Cour des Aides de Clermont-Ferrand," is dated July 12, 1651, in which he complains that in the "Prologue" of certain theses on philosophy read in this judge's presence June 25, 1651, he had been accused of appropriating credit for the Torricellian experiment.

"In the year 1644 someone wrote from Italy to Rev. Fr. Mersenne, Minimite at Paris, that the experiment we are discussing had been done, without specifying in any way who was its author. So in fact he remained unknown to us. Fr. Mersenne tried to repeat it at Paris, and not being entirely successful with it, he stopped and thought no more about it. Then, having been at Rome on other business, and being exactly informed as to the means of carrying it out, he returned thence fully instructed.

This news having been brought us at Rouen, where $I$ then was, in the year 1646, we did this Italian experiment according to the directions of Fr. Mersenne, and, having been entirely suo 
cessful with it, I repeated it several times; and being by this frequent repetition entirely assured of its truth, I deduced from it consequences, to test which I did new experiments very different from that one, in the presence of more than five hundred persons of all sorts and conditions, and among them five or six Jesuit fathers of the College at Rouen.

To render to others and myself justice due, I had printed, in the year 1647 , the experiments which $I$ had done a year earlier in Normandy.

(This was the abstract translated above. The complete treatise was never published; only fragments of it are known.-W. J F.)

\section{A POWER TEST FOR PHYSICS PUPILS.}

BY WILLIS E. TOWER, Englewood High School, Chicago.

The following test has been used several years at this school. It always arouses interest. Many are surprised at the power required in elimbing stairs. A husky football player will develop over 1.5 horse power, while a girl walking upstairs at an ordinary pace will use 0.2 horse power or more. The directions given below are the same as those handed to our pupils.

Purpose: To test the horse power of a person while running upstairs.

Apparatus: A stop wateh, a meter stick. (From two to five persons may work together in performing this experiment.)

Directions: (a) Count the number of steps from the first floor to the landing above and find by measurement the average height of each step. Then eompute the distance one rises in going up this flight of steps, or determine the height elimbed in any other way.

(b) Determine by the use of the stop watch the exact time required to run up the steps, using the average of at least three trials. It may require some praetice to learn to use the stop wateh properly. Be eareful that the watch is started at just the instant the person begins to rise, and that it is stopped just when the person reaches the top. Be careful not to exert yourself unduly in making the test.

(c) Compute the work done in running up the steps, using the person's weight in pounds and the height of the stairs in feet.

(d) Compute the power developed in horse power and in foot pounds per second.

(e) Place all measurements and results in tabular form. Record the hour and date of making the test.

(f) Make a second test for horse power by going upstairs as before, only this time going at the rate you ordinarily employ. Make three trials and record as before.

Questions: 1. If a man-power is one-seventh of a horse power, how fast should you go upstajrs in order to exert just one man-power? How does this compare with your usual speed in going upstairs?

2. How much time did you require to perform this experiment? How muoh time to write it up?

3. What use can you make of the results of this experiment? 